\title{
Stool microscopy in screening for steatorrhoea
}

\author{
SALIL K. GHOSh, J. M. LitTLEWOOD, D. GODDARD, AND A. E. STEEL \\ From the Departments of Paediatrics and Infectious Diseases at Seacroft Hospital, the Neonatal Unit at \\ St. Mary's Hospital, the Public Health Laboratory, Leeds, and the Department of Biochemistry, \\ Killingbeck Hospital, Leeds
}

SUMMARY A prospective study is described comparing microscopy of random faecal specimens for the presence of neutral and split fat by a relatively simple, cheap, and rapid method with standard chemical estimation of faecal fat. The method of microscopy was found to be reliable in excluding steatorrhoea in children over the age of 3 months.

Quantitative biochemical estimation of faecal fat content is an accepted routine procedure for investigation of malabsorption. The standard technique is to collect all samples of faeces passed during a three- or five-day period and to estimate the fat content in the sample. This method is liable to show false negative results due to incomplete collection (Ditchburn et al., 1971) or to irregular bowel action. Stool markers have been used to improve the situation but still the method is time-consuming and needs close supervision, particularly in children. Microscopy of the stool for faecal fat has been recommended for the detection of steatorrhoea (Hurst, 1942); the method has also been criticised by Cooke et al. (1946). There is little published work to substantiate the value of microscopy (Andersen, 1945). Drummey et al. (1961) have demonstrated a good correlation between microscopy of the stool for fat and its quantitative estimation in adult patients. The present report describes a prospective comparative study of microscopy of a random specimen of faeces and the result of a timed collection of faeces examined for fat by chemical methods for detecting steatorrhoea in children.

\section{Material}

One hundred children ( 46 boys and 54 girls) aged between 11 days and 15 years from the paediatric and infectious diseases departments of Seacroft Hospital and the Neonatal Unit at St. Mary's Hospital, Leeds, were included in the study. Fat intake exceeded 35 $\mathrm{mmol} /$ day in neonates, $175 \mathrm{mmol} / \mathrm{day}$ in older infants, and $210 \mathrm{mmol} /$ day in children.

Seventy patients had carmine and four patients had polyethylene glycol (PEG) as a stool marker;

Received for publication 26 October 1976
26 patients had no marker. Stool samples were collected for three consecutive days in 57 patients, for five consecutive days in 37 patients, and just one sample of faeces was obtained for each of the four cases who had a PEG marker. Stool collection was done in 88 patients during their stay in hospital and as outpatients in 12 .

Care was taken that the patient did not receive any suppository or mineral oil before or during the sampling period, and the infants had no oily material (ie, cream) applied to the perineum. Apart from the samples which contained PEG (these were collected in glass jars) all other faecal material was collected in PVC screwtop jars. In neonates, plastic linings were used underneath nappies to facilitate collection.

\section{Method}

Total faecal fat content was estimated by the method of van de Kamer and colleagues (1949). PEG measurement was done according to the method of Hydén (1965).

Microscopy was performed and interpreted along the lines outlined by Drummey and colleagues (1961) with slight modification. The specimen of faeces is thoroughly mixed with the applicator stick and small representative amounts, about $5 \mathrm{~mm}$ in diameter, are placed on two microscopic slides. In the case of fluid stool, a similar amount is picked up by capillary pipette.

\section{NEUTRAL FAT}

Two drops of water are added to the formed stool specimen on the first slide and thoroughly mixed with an applicator stick; two drops of $95 \%$ ethyl alcohol are added and mixed again. One to two drops of a saturated solution of Sudan III in $95 \%$ ethyl alcohol are then added with the edge of the cover 
slip. The cover slip is applied and the preparation is examined under the microscope, using a dry lens (magnification $\times 400$ ) for yellow or pale orange refractile fat globules.

\section{SPLIT FAT}

Several drops of $36 \%$ acetic acid are added to the stool specimen on the second slide and mixed to homogeneous consistency, followed by several drops of Sudan III. The preparation is then mixed by the edge of the cover slip. The slide is gently heated, with the cover applied, over an alcohol burner until it starts to boil. The process is quickly repeated three times and the slide is then promptly examined under the same lens while the preparation is still warm.

The stained free fatty acids appear (when warm) as deep orange, oily masses (Fig. 1); as the preparation cools down spicules and soap structures develop, which resemble the pinna of the ear.

The distinction between neutral and split fat is important and useful clinically, for the presence of the former is commonly associated with pancreatic disease.

In each microscopic field $(a)$ the number of fat particles are counted, and $(b)$ the size of the particles is noted in comparison with that of an average red blood cell $(7 \mu \mu)$.

In order to simplify the microscopical procedure, the only change we made in the method employed by Drummey et al. (1961) was to compare the diameter of the fat particles arbitrarily with that of a red blood cell (RBC) instead of actually measuring the diameter by a micrometer eye-piece. Therefore, our microscopy result was interpreted as follows:

+ up to 100 particles per field, smaller than a $\mathrm{RBC}$ in size, much faecal matter in the background (Fig. 2)

++ over 100 particles, of size equal to that of RBC, relatively less faecal matter in the background

+++ over 100 particles, size larger than $R B C$, and practically no faecal matter in the background (Fig. 1).

The results were recorded for neutral and split fat.

To ensure there was no variation between different parts of the same faecal specimens, multiple microscopies were performed from different parts of the same faecal specimen with identical results.

\section{Results}

The results of microscopy for split fat have been plotted against the biochemical findings in Figures 3 and 4. In + group, all cases (29) excreted less than $14 \mathrm{mmol} /$ day of faecal fat; in this group the correlation between microscopy and biochemical estimation is excellent. In group ++ there were eight patients excreting fat between 15 and $35 \mathrm{mmol} /$ day and 17 (excluding five patients under 3 months of age) excreting 0-14 mmol/day; therefore, in this group

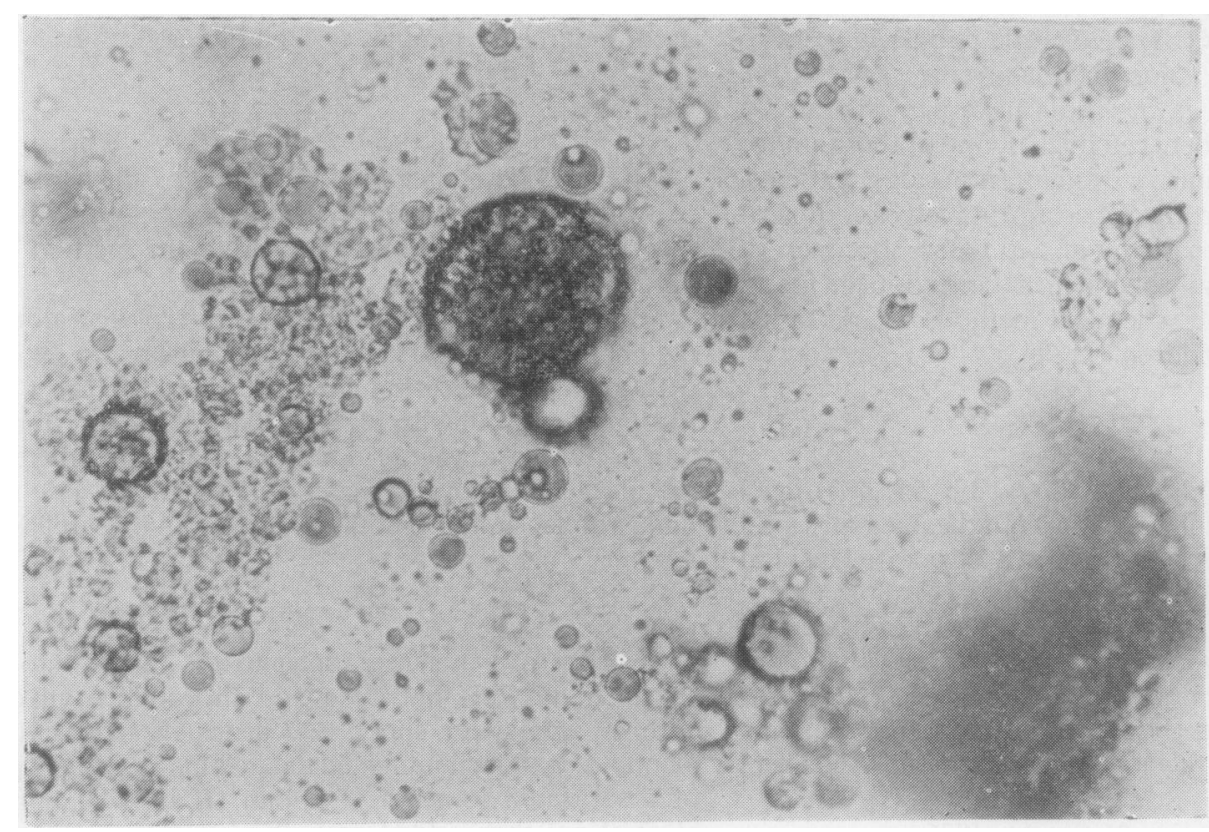

Fig. 1 Photomicrograph of stool showing microscopy score of +++ for faecal fat $(\times 290)$. 


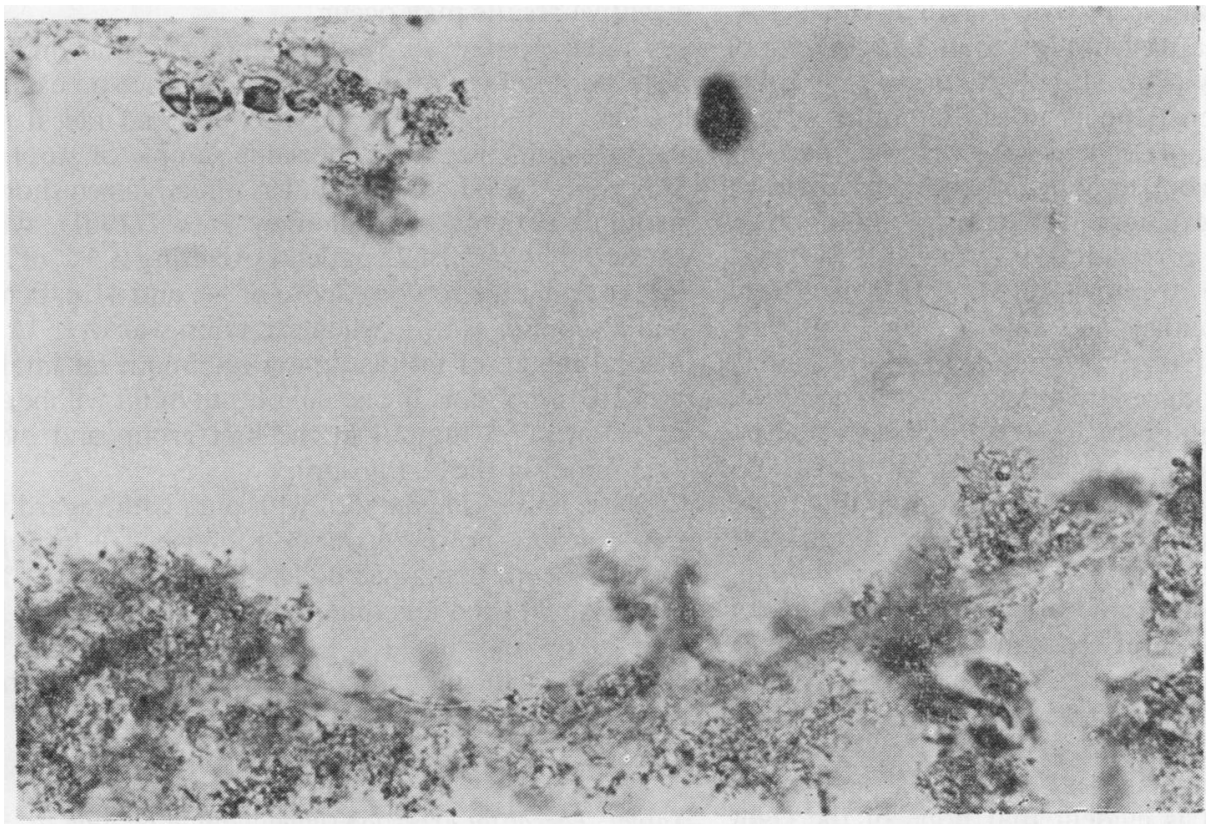

Fig. 2 Photomicrograph of stool showing microscopy score of + for faecal fat $(\times 290)$.

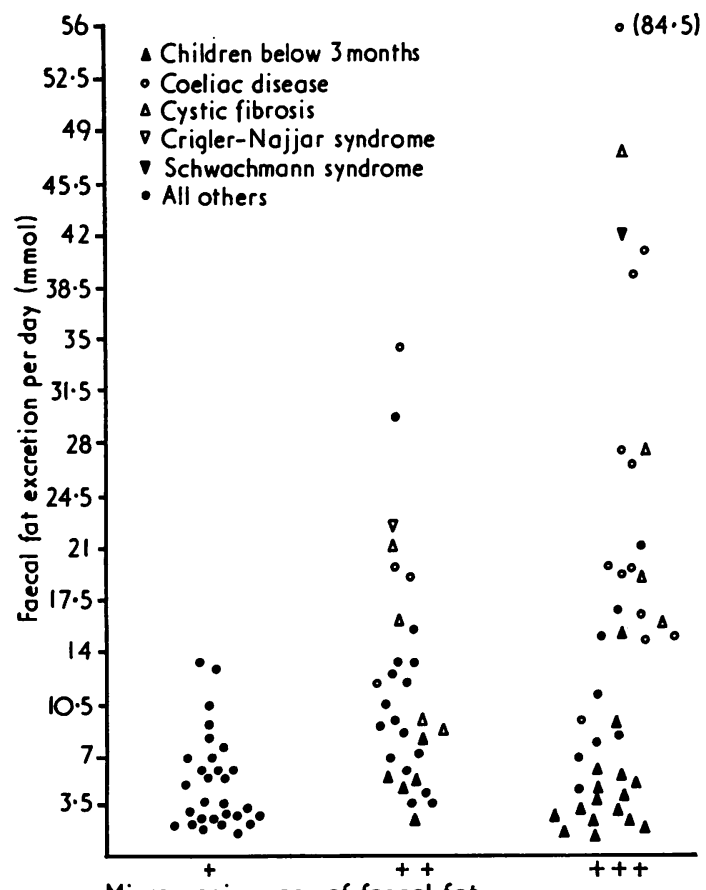

Fig. 3 Comparison of quantitative estimation of faecal fat with microscopy in 100 children of all ages according to final diagnosis.

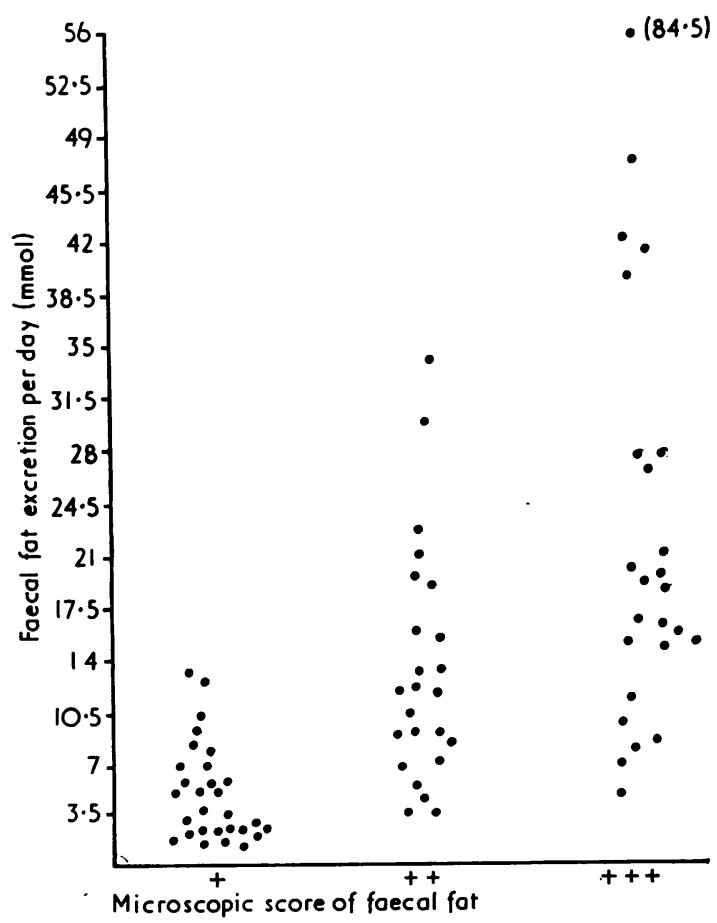

Fig. 4 Comparison of quantitative estimation of faecal fat with microscopy in 79 children (over 3 months old) irrespective of final diagnosis. 
only eight ( $32 \%)$ are correctly correlated. The +++ group shows a scatter from less than 3.5 to $85 \mathrm{mmol}$ faecal fat per day (Fig. 3), but the picture improves substantially when patients under 3 months of age are excluded (Fig. 4). There were only five patients in the +++ group among 25 (patients under 3 months of age excluded) excreting $35 \mathrm{mmol} /$ day, giving a positive correlation only on $20 \%$ of cases. Of the rest of the 20 cases (excluding 16 babies aged less than 3 months) showing +++ result by microscopy, $17(70 \%)$ produced $15-35 \mathrm{mmol} /$ day and six (30\%) produced $0-14 \mathrm{mmol} /$ day of faecal fat.

Although the numbers are small it is clear that no child excreting over $14 \mathrm{mmol} /$ day of faecal fat belonged to group + , and no patient excreting more than $35 \mathrm{mmol} /$ day belonged to either + or ++ group.

Microscopic scores of ++ or +++ do not necessarily indicate that the patient has steatorrhoea but that this should be excluded by chemical estimation of faecal fat. This is particularly important in babies under 3 months of age, where scores are commonly ++ or +++ .

From Fig. 3 it is evident that none of the eight cases of cystic fibrosis, 16 cases of coeliac disease (proved by jejunal biopsy), and one case of Shwachman syndrome would have been missed if the score of + is accepted as normal (excluding steatorrhoea); ie, There is not a single false negative result in the + group.

\section{Discussion}

Though biochemical estimation of faecal fat excretion, as an index of dietary fat absorption and digestion, has been in routine use for many years, the disadvantages of the method are well known. Meticulous collection of all the faecal samples under careful supervision of the nursing staff for three to five days has its practical difficulties apart from handling and storage. Collection is particularly difficult in young children and infants. Irregular bowel action may pose a problem. Ditchburn et al. (1971), by using radioactive faecal markers, have shown that only $48 \%$ of hospitalised adult patients provided a complete collection, even in a teaching hospital.

The use of faecal markers has improved accuracy of the collection. With the administration of a continuous marker only one sample of stool need be collected for faecal fat estimation (Lee et al., 1969; Wilkinson, 1971). It is, however, important to ensure that the marker has been taken in three divided doses continuously, at least for five days-which may, at times, be a problem at home. The stool sample must be collected on the sixth day, otherwise false negative results may occur.

In the present study, our emphasis was on the correlation of the microscopic appearance on examination of a small random specimen and faecal fat content estimated from the same sample of stool in children. A good correlation has already been shown in adult patients by Drummey et al. (1961), who showed that $86 \%$ of 22 patients excreting $0-5 \%$ of fat intake had a microscopy score of + , and 41 patients had a score of +++ when excretion was over $15 \%$ of oral intake of fat (assuming minimum fat intake was $210 \mathrm{mmol} / \mathrm{day}$, the actual output of fat will be at, or below, $17.5 \mathrm{mmol} / \mathrm{l}$ in the first group and over $31.5 \mathrm{mmol}$ in the last group).

These findings agree well with ours with regard to the + group; however, our ++ and +++ groups by microscopy contained no less than 43 cases (61\%) including 20 aged less than 3 months, excreting 0-14 $\mathrm{mmol} /$ day and also +++ group contained 15 cases (37\%), including one aged less than 3 months, excreting $15-35 \mathrm{mmol} / \mathrm{day}$ (see Table).

Table Faecal fat excretion (mmol/day) in relation to microscopic score in 100 children

\begin{tabular}{lcccc}
\hline $\begin{array}{l}\text { Fat excretion } \\
\text { (mmol/day) }\end{array}$ & \multicolumn{4}{l}{ Microscopic score for split fat } \\
\cline { 2 - 5 } & + & ++ & +++ & Total \\
\hline $0-14$ & 29 & 17 & 6 \\
& & $(5)$ & $(15)$ \\
$15-35$ & 0 & 8 & 14 \\
& 0 & 0 & $(1)$ \\
Over 35 & 29 & 30 & 5 & 72 \\
Total & $(100 \%)$ & & 41 & 23 \\
& & & 100 \\
\end{tabular}

Infants less than 3 months in parentheses.

The discrepancy is largely accounted for by infants of less than 3 months. Therefore, in paediatric patients it seems that by microscopy it is possible to identify patients who do not have steatorrhoea, and in the present study a microscopy result of only one + was never associated with faecal fat excretion of more than $14 \mathrm{mmol} / \mathrm{day}$ whatever the age of the child.

It is interesting to note the position of the 21 infants aged less than 3 months, for although they are placed in the +++ group (15 infants excreting $0-14 \mathrm{mmol} /$ day and one excreting $15.5 \mathrm{mmol} /$ day faecal fat) or in the ++ group (five excreting $0-14 \mathrm{mmol} / \mathrm{day}$ ), it is well known that the infants have a low coefficient of fat absorption, approaching $85 \%$ on cow's milk (Weijers and van de Kamer, 1953). The ++ and +++ microscopy results, in the presence of daily fat output of below $14 \mathrm{mmol}$, are a visual reflection of the increased percentage of 
fat which is present in the faeces of the infants fed on milk.

As noted above, stools from some patients with pancreatic disease show a marked increase of neutral fat (Drummey et al., 1961). Among our patients four out of eight patients with cystic fibrosis and the case of Shwachman syndrome revealed excessive neutral fat on stool microscopy.

Apart from ease of collection of the sample, other advantages of the microscopic assessment of faecal fat are economy of time (that is, it takes less than $\mathbf{1 0}$ minutes as opposed to about 90 minutes in biochemical measurement), the cost of material for microscopic analysis is negligible, and this method is free from the hazards of homogenisation of faecal matter which is undertaken during biochemical assessment of faecal fat content.

We thank Dr J. Stevenson and Dr H. Pullen of the Infectious Diseases Department, Seacroft Hospital, who permitted us to include patients under their care; the sisters and staff of Seacroft Hospital and St. Mary's Hospital; Mr K. Bramald, Bacteriology Department, for technical help; Dr G. L. Gibson, Director of the Regional Public Health Laboratory for helpful advice; and Mrs C. Silburn for secretarial help.

\section{References}

Andersen, D. H. (1945). Celiac syndrome 1: determination of fat in feces. American Journal of Diseases of Children, 69, 141-151.

Cooke, W. T., Elkes, J. J., Frazer, A. C., Parkes, J., Peeney, A. L. P., Sammons, H. G., and Thomas, G. (1946). Anomalies of intestinal absorption of fat. Quarterly Journal of Medicine, 15, 141-155.

Ditchburn, R. K., Smith, A. H., and Hayter, C. J. (1971). Use of unabsorbed radioactive marker substances in a re-assessment of the radioactive triolein test of fat absorption. Journal of Clinical Pathology, 24, 506-514.

Drummey, G. D., Benson, J. A. Jr., and Jones, C. M. (1961). Microscopical examination of the stool for steatorrhea. New England Journal of Medicine, 264, 85-87.

Hurst, A. (1942). The pathogenesis of the Sprue-syndrome. Guy's Hospital Reports, 91, 1-21.

Hydén, S. (1965). A turbidimetric method for the determination of higher polyethylene glycols in biological materials. Lantbrukshögskolans Annaler, 22, 139-145.

van de Kamer, J. H., Ten Bokkel Huinink, H., and Weijers, H. A. (1949). Rapid method for the determination of fat in faeces. Journal of Biological Chemistry, 177, 347-355.

Lee, M. F., Temperley, J. M., and Dick, M. (1969). Estimation of faecal fat excretion using cuprous thiocyanate as a continuous marker. Gut, 10, 754-759.

Weijers, H. A. and van de Kamer, J. H. (1953). Coeliac disease. Acta Paediatrica, 42, 24-33.

Wilkinson, R. (1971). Polyethylene glycol 4000 as a continuously administered non-absorbable faecal marker for metabolic balance studies in human subjects. Gut, 12, 654-660. 